\title{
latrogenic Gallstone Pancreatitis Complicated by Cholangitis: Post-Cholecystectomy Clip as a Nidus for Common Bile Duct Stone Formation
}

\author{
Mohd Amer AlSamman ${ }^{\mathrm{a}, \mathrm{b}, \mathrm{d}}$, Abdelmoneim Mostafa ${ }^{\mathrm{b}}$, \\ Jason D. Ferreira ${ }^{b, c}$
}

\begin{abstract}
Cholecystectomy is one of the most common surgical procedures in clinical practice. Laparoscopic cholecystectomy has become the gold standard for the management of symptomatic gallstone disease due to its minimally invasive nature and safety with quoted complication rates of under $5 \%$. Surgical clip migration into the bile duct with resultant stone formation is a rare complication of laparoscopic cholecystectomy. Here we present a case of cholangitis in addition to gallstone pancreatitis as a result of surgical clip migration into the bile duct leading to stone formation.
\end{abstract}

Keywords: Laparoscopic cholecystectomy; Surgical clip migration; Choledocholithiasis

\section{Introduction}

Symptomatic cholelithiasis is a common presentation that is often definitively treated with cholecystectomy. In the United States, over half a million cholecystectomies are performed annually [1]. Since the introduction of minimally invasive surgical technique, laparoscopic cholecystectomy has become the gold standard for the management of symptomatic gallstone disease $[1,2]$.

Complication rates associated with laparoscopic cholecystectomy are commonly cited to be $<5 \%$ and are often categorized as early or late based on their timing after the procedure. Early complications include bile duct injuries, biliary leaks, retained common bile duct stones, bleeding, and wound infections. Most complications are minor and easily managed if

Manuscript submitted January 20, 2019, accepted February 22, 2019

aDepartment of Medicine, the Warren Alpert Medical School of Brown University, Providence, RI, USA

${ }^{\mathrm{b}}$ The Miriam Hospital, Providence, RI, USA

'University Gastroenterology, Providence, RI, USA

${ }^{\mathrm{d} C}$ Corresponding Author: Mohd Amer AlSamman, Department of Medicine, the Warren Alpert Medical School of Brown University, Providence, RI, USA. Email: alsamman.amer@gmail.com

doi: https://doi.org/10.14740/gr1147 recognized early; however, serious early complications such as bile duct injuries can be associated with prolonged hospital stays, requirement for further surgeries and endoscopic procedures, as well as potential long-term consequences such as biliary strictures which can seriously impact a patient's quality of life and results in significant health care expenditure [3, 4].

Late complications of cholecystectomy are often underrecognized and can include chronic right upper quadrant (RUQ) pain, change in bowel habits, biliary strictures, and rarely surgical clip migration. Migration of surgical clips into the bile duct with resultant biliary stone formation has been previously described but remains very rare despite the number of laparoscopic cholecystectomies performed annually [5]. Apart from migration into the biliary tree, surgical clips have also been implicated in duodenal ulcer formation and vascular embolism $[6,7]$.

\section{Case Report}

Here we present an 84-year-old male patient with history of hypertension, diabetes mellitus, hyperlipidemia, and peptic ulcer disease who underwent laparoscopic cholecystectomy 5 years prior and presented to the hospital with nausea, vomiting, postprandial abdominal pain, and dark colored urine. Vital signs showed heart rate 112 beat per minute, temperature $39{ }^{\circ} \mathrm{C}$, blood pressure $138 / 85 \mathrm{~mm} \mathrm{Hg}$, and respiratory rate 19 breaths per minute. Laboratory workup showed elevated liver function tests with an AST $248 \mathrm{IU} / \mathrm{L}$, ALT $321 \mathrm{IU} / \mathrm{L}$, alkaline phosphatase $362 \mathrm{IU} / \mathrm{L}$, total bilirubin $8.8 \mathrm{mg} / \mathrm{dL}$, direct bilirubin $5.5 \mathrm{mg} / \mathrm{dL}$, and lipase 1,532 IU/L. CT scan of the abdomen and pelvis with IV contrast showed peripancreatic stranding with common bile duct dilation to more than $1 \mathrm{~cm}$ with no evidence of mass or stones. He subsequently underwent an endoscopic retrograde cholangiopancreatography (ERCP) that showed dilation of the common bile duct up with a $2-\mathrm{cm}$ narrowing noted at the distal common bile duct, and a large stone $8 \mathrm{~mm}$ in diameter in the middle third of main bile duct with metallic surgical clip shadow in the center (Fig. 1). A biliary sphincterotomy was made where pus and a cholecystectomy clip engulfed within a stone swept out (Fig. 2), mostly suggesting that the clip had eroded into the biliary tree and become a nidus for stone formation. One 10 French by $9 \mathrm{~cm}$ plastic stent was placed into the common bile duct to ensure adequate bil- 


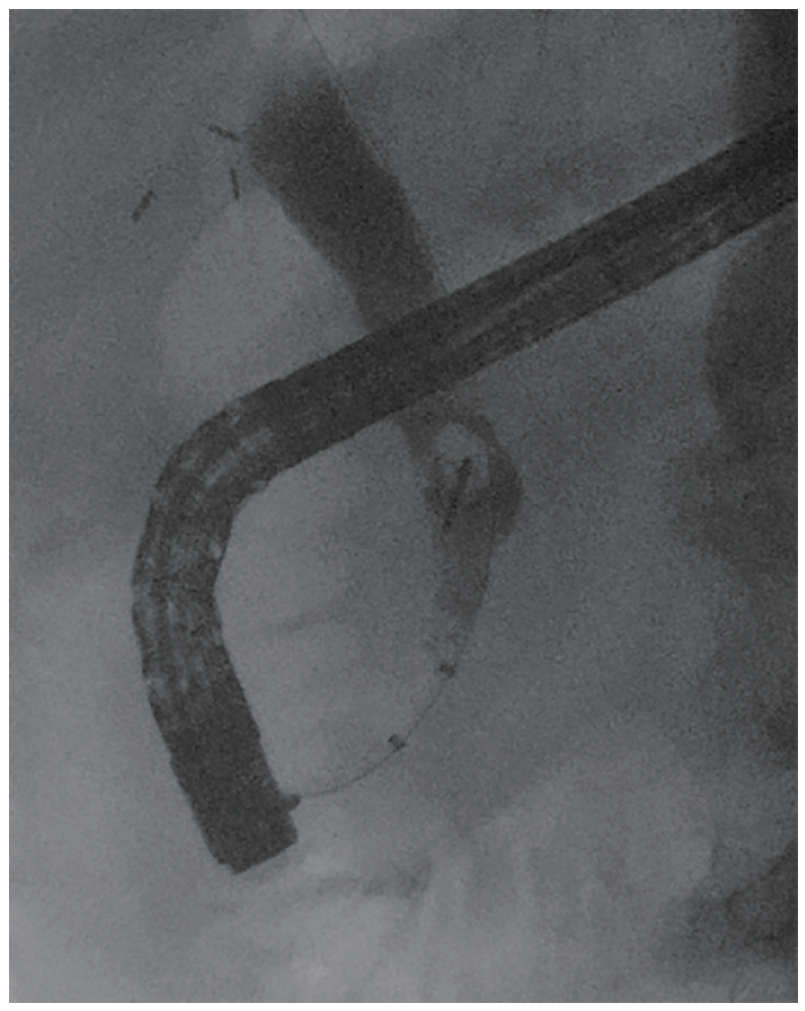

Figure 1. Endoscopic retrograde cholangiopancreatography (ERCP) image showing a filling defect suggestive of a stone with a surgical clip inside.

iary drainage. After recovery from his pancreatitis and proper antibiotic treatment, he was discharged home. Four weeks

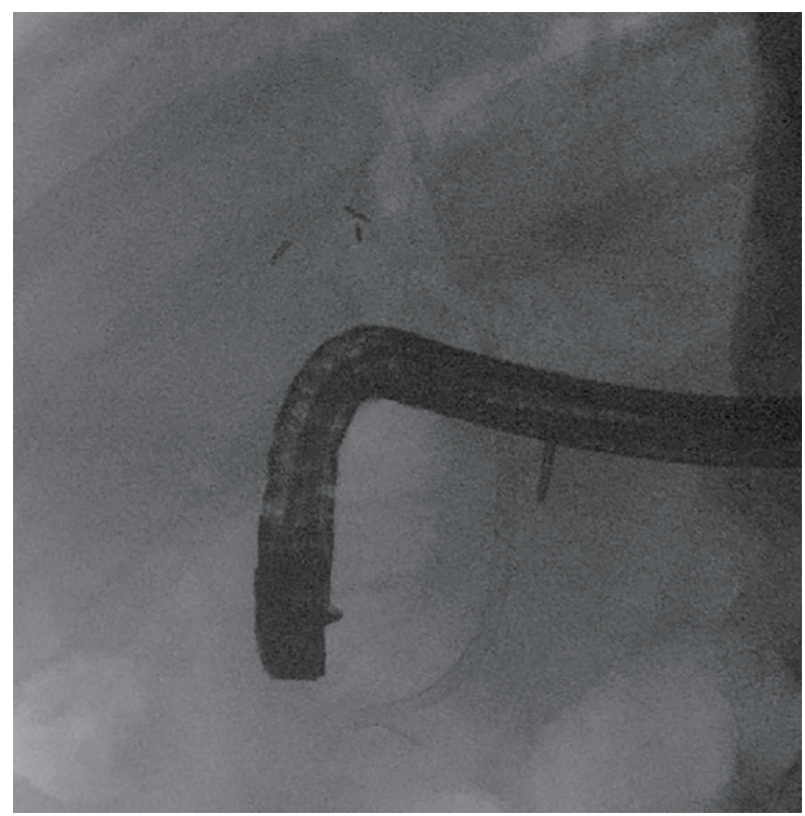

Figure 3. Endoscopic retrograde cholangiopancreatography (ERCP) image after removal of the stone and the surgical clip, with normal appearing common bile duct and biliary tree.

later, a follow-up ERCP for stent removal was performed that showed normal common bile duct and biliary tree (Fig. 3).

\section{Discussion}

Surgical clips eroding into the biliary tree and serving as a nidus

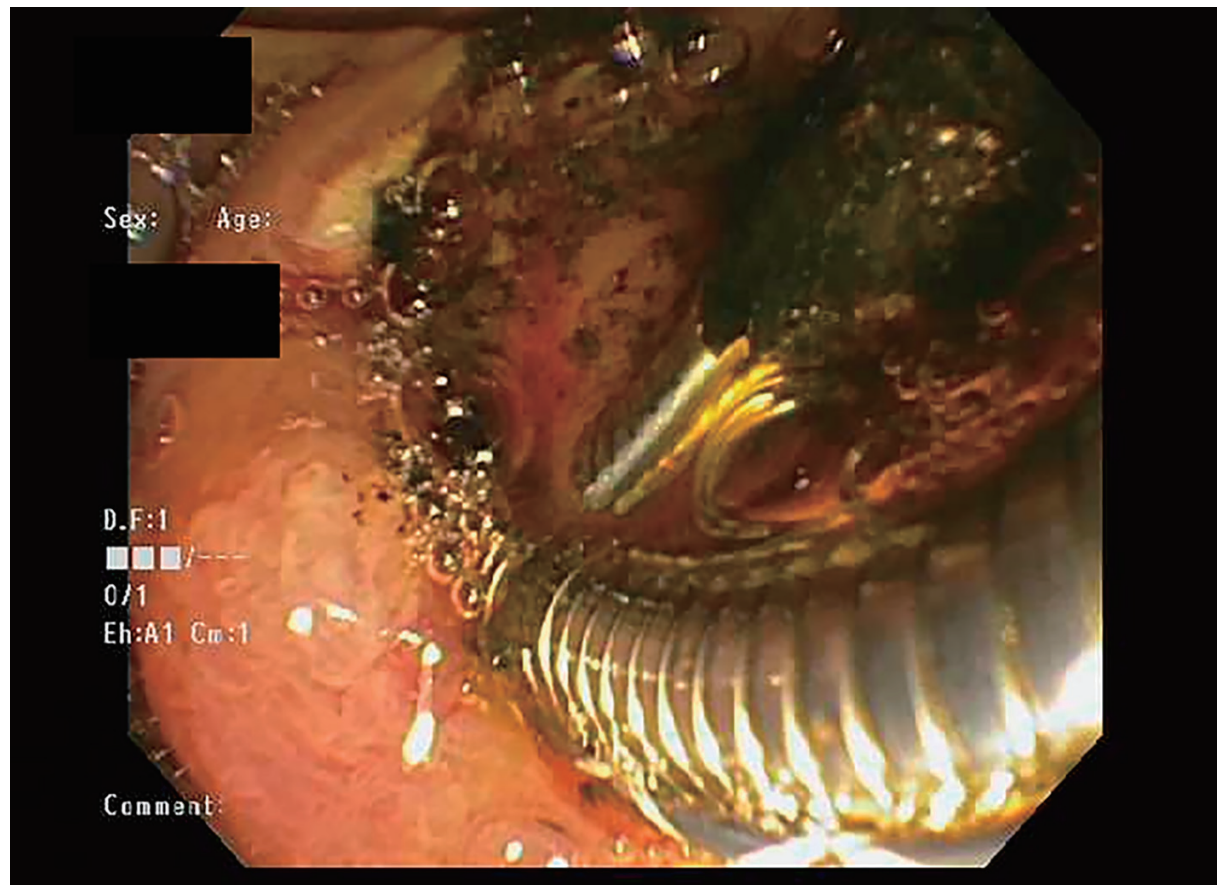

Figure 2. Endoscopy image showing a surgical clip engulfed within a stone. 
for bile duct stone formation is a rare, but increasingly reported complication of cholecystectomy. Walker was the first to report this complication in $1979[8,9]$ and since then a few more cases have been reported but there are no comprehensive data about the exact incidence. The presentation and management of clip-induced gallstones are no different than the traditional variety and it is thought that clip erosion into the bile duct is a slow process that occurs over the course of months to years. It is not clearly understood how surgical clips would be able to migrate through the layers of an intact biliary duct; however, it is hypothesized that clipping of the cystic duct remnant can lead to ischemic necrosis which weakens the biliary wall leading to eventual clip migration [10]. It is also possible that technical factors at the time of surgery may play a role in leading to clip migration with inadvertent clip dislodgement, incorrect clip placement, and/or biliary anatomic variants allowing for a point of entry for the clip into the common bile duct [11].

Our patient had a common bile duct stone where postcholecystectomy surgical clip acted as precursor; however, it is unclear why he developed acute pancreatitis. As the stone was situated at a higher level than the pancreatic duct, maybe there was another stone that passed, or less likely, an abnormal anatomy; nonetheless, this should have been detected on imaging, or, this was secondary to an idiopathic etiology.

\section{Conclusion}

Surgical clip migration serving as a nidus for common bile duct stone formation is a rare late complication of laparoscopic cholecystectomy. Since first being reported in 1979, there have been few documented cases and therefore the incidence of this complication is unknown. It is hypothesized that the clip can migrate though the biliary tract due to degradation of the biliary wall induced by ischemic pressure necrosis from the clip's placement. Regardless of mechanism, it is important for gastroenterologists and surgeons to counsel patients that biliary stones may still form after cholecystectomy. Further studies should be aimed at determining the incidence of this late surgical post-cholecystectomy complication.

\section{References}

1. Ellison EC, Carey LC. Cholecystectomy, cholecystostomy, and intraoperative evaluation of the biliary tree. In Baker JR, Fishcer JE, eds. Mastery of Surgery. 4th ed. Philadelphia: Lippincott Williams \& Wilkins, 2001.

2. Lee VS, Chari RS, Cucchiaro G, Meyers WC. Complications of laparoscopic cholecystectomy. Am J Surg. 1993;165(4):527-532.

3. Brutvan FM, Kampschroer BH, Parker HW. Vessel clip as a nidus for formation of common bile duct stone. Gastrointest Endosc. 1982;28(3):222-223.

4. Margolis JL. Recurrent choledocholithiasis due to hemostatic clip. Arch Surg. 1986;121(10):1213.

5. Farr CM, Larson C, Gladen HE, Witherspoon L, Lesperance R, Moseley D. An iatrogenic gallstone with pancreatitis. J Clin Gastroenterol. 1989;11(5):596-597.

6. Matsuura T, Kanisawa Y, Sato T, Saito T, Hirata K. Migration of "endo-clips" into common bile-duct after laparoscopic cholecystectomy. Lancet. 1992;340(8814):306.

7. Raoul JL, Bretagne JF, Siproudhis L, Heresbach D, Campion JP, Gosselin M. Cystic duct clip migration into the common bile duct: a complication of laparoscopic cholecystectomy treated by endoscopic biliary sphincterotomy. Gastrointest Endosc. 1992;38(5):608-611.

8. Walker WE, Avant GR, Reynolds VH. Cholangitis with a silver lining. Arch Surg. 1979;114(2):214-215.

9. Onghena T, Vereecken L, Van den Dwey K, Van Loon C. Common bile duct foreign body: an unusual case. Surg Laparosc Endosc. 1992;2(1):8-10.

10. Tsumura H, Ichikawa T, Kagawa T, Nishihara M, Yoshikawa K, Yamamoto G. Failure of endoscopic removal of common bile duct stones due to endo-clip migration following laparoscopic cholecystectomy. J Hepatobiliary Pancreat Surg. 2002;9(2):274-277.

11. Cetta F, Baldi C, Lombardo F, Monti L, Stefani P, Nuzzo G. Migration of metallic clips used during laparoscopic cholecystectomy and formation of gallstones around them: surgical implications from a prospective study. J Laparoendosc Adv Surg Tech A. 1997;7(1):37-46. 